Revista Iberoamericana, Vol. LXXVI, Núm. 232-233, Julio-Diciembre 2010, 855-874

\title{
LA POÉTICA MATEMÁTICA DE HUAN LUIS MARTÍNEZ
}

\author{
POR \\ MARCELO Rioseco \\ University of Cincinnati
}

Aunque el Logos es común, la mayoría vive como si tuviera una inteligencia particular

Fr. 2, Sexto, adv, math. VII 133.

Heráclito

La palabra del pensar es pobre en imágenes y no tiene atractivo.

La palabra del pensar descansa en una actitud que le quita embriaguez y brillo a lo que dice. Sin embargo, el pensar cambia el mundo. Lo cambia llevándolo a la profundidad de pozo, cada vez más oscura, de un enigma, una profundidad que cuanto más oscura es, más alta claridad promete

Heráclito (Fragmento 50) Heidegger

A finales de la década de los setentas, el poeta chileno Juan Luis Martínez escribe dos libros marcadamente experimentales, La nueva novela (1977) y La poesía chilena (1978). Con estos textos, Martínez inaugura la Neovanguardia en Chile y se inserta en lo que la crítica ha llamado la "Nueva poesía chilena”.

\footnotetext{
1 Se denomina nueva poesía chilena a la poesía escrita en Chile y en el exterior a partir del golpe militar de 1973, pero que corresponde a autores que comienza a publicar a partir de 1977 y por un espacio de al menos 10 años. Si bien es cierto, muchos de sus trabajos creativos están signados por las circunstancias políticas del país y determinados, de una u otra manera, por el quiebre histórico del golpe militar, no siempre estos autores se proponen expresar la realidad política y social que viven. Ese es el caso de una de las corrientes de la Neovanguardia donde estarían poetas como Juan Luis Martínez, Diego Maquieira y Rodrigo Lira. Ver "Poesía chilena de la última década (1977-1987)” de Iván Carrasco (1989), “La poesía de la Generación de los 80: Valoración se fin de siglo” de Andrés Morales (2000) y “Grupo poetas del 70 o la supuesta generación del 80” de Julio Espinosa (2005).
} 
Inicialmente, la Neovanguardia literaria contiene una primera línea más ortodoxa compuesta por los poetas Juan Luis Martínez (1942), Raúl Zurita (1950), Cecilia Vicuña (1948) y Diego Maquieira (1953). Otra línea que reúne lo experimental con lo urbano (sin caer en el juego lingüístico ni en la poesía visual) se compone de Elvira Hernández (1951), Alexis Figueroa (1956) y Tomás Harris (1956). El crítico chileno Iván Carrasco señala a Valparaíso como centro fundador de la Neovanguardia a finales de los 60’s y comienzos de los 70's y de paso indica la importancia de quien fuera la figura central e indiscutida de esta corriente, el poeta porteño Juan Luis Martínez. "Este grupo inicial se proyectó luego en Santiago por intermedio de Zurita en el C.A.D.A.”3 (Carrasco La poesía 36). La Neovanguardia es heredera, por supuesto, de la vanguardia histórica, pero se le suma a esta influencia la de la antipoesía de Nicanor Parra. Aunque ningún miembro de la Neovanguardia o, más aún, de la Nueva poesía chilena es un explícito discípulo parriano, el influjo de la antipoesía de Nicanor Parra en la poesía de esa época fue evidente. ${ }^{4}$ Pero no de una manera directa. La Neovanguardia tomó de Parra algunos de los procedimientos de la escritura antipoética y los llevó a un extremo. Quizás el procedimiento que le sea más común a un gran número de poetas de la Neovanguardia (y de la Nueva poesía en general) sea la problematización de la voz poética tradicional, esto es, la voz del poeta lírico. Parra desacraliza la voz poética, la rebaja hasta el límite de lo popular o, en otros momentos, la divide en varias voces al modo de un gran poema dramático. Por su parte, la Neovanguardia escinde el yo hasta hacerlo desaparecer (Juan Luis Martínez) o lo reparte en una gran voz que no es ninguna voz (Maquieira en los Sea Harrier). A nivel latinoamericano, la Neovanguardia exhibe una clara correspondencia con el espíritu trasgresor y experimental de la vanguardia histórica y guarda cercanas similitudes en sus prácticas con las propuestas de la Poesía concreta brasileña.

Su principal característica es la recuperación de las inquietudes de las vanguardias europeas de principios del siglo xx, pero re-contextualizándolas. Estarían en estrecha relación con la poesía concreta brasileña y sus cultores, por lo que al expandir el espacio de

2 Es interesante la opinión de Andrés Morales quien ve en la relectura de La nueva novela el inicio, al menos simbólico, de la Neovanguardia. "Siguiendo el esquema propuesto por Carrasco, la poesía neovanguardista avanza en el territorio del experimentalismo y se funda en la reedición de los contenidos de las vanguardias tradicionales orientados por la relectura del gran poeta viñamarino Juan Luis Martínez, autor de libros tan significativos como La nueva novela (1977) y La poesía chilena (1978)”. (Morales 244).

3 El grupo C.A.D.A. (Colectivo de Acciones de Arte) estuvo integrado por el poeta Raúl Zurita, la narradora Diamela Eltit, los artistas visuales Juan Castillo y Lotty Rosenfeld, y el sociólogo Fernando Balcells.

4 "De particular interés es la vinculación de la antipoesía con el sector llamado provisoriamente Neovanguardista, constituido fundamentalmente en Valparaíso en torno a Juan Luis Martínez, Raúl Zurita y Juan Cameron, con la participación indirecta de Adolfo Nordenflyncht y otros, y luego en Santiago alrededor del grupo C.A.D.A. (R. Zurita, G. Muñoz) y otros autores como Rodrigo Lira, D. Maquieira, C. Cociña, etc”. (Carrasco Antipoesía y neovanguardia 37).

ISSN 0034-9631 (Impreso) 
escritura, rompiendo con las normas de construcción del poema tradicional, incorporarían elementos no verbales de índole gráfica, objetal y lógica, y despersonalizarían al sujeto, multiplicándolo o escindiéndolo. (Espinosa 125)

Andrés Morales destaca los quiebres de la Neovanguardia con respecto al poema tradicional, la incorporación de elementos no verbales fundamentalmente de carácter visual, el predominio del lenguaje lógico derivado de las ciencias y la total ruptura y alejamiento con el yo de la poesía lírica ya sea para eliminarlo (y en consecuencia, eliminar de paso al autor) o para escindirlo en distintas voces fragmentadas y diversas. Los poetas de la Neovanguardia son conscientes en exceso del lenguaje y se interesan por los problemas de la percepción y los límites del conocimiento humano. Es una poesía autoreflexiva donde el lenguaje es tema y reflexión del poema. No propician ni el ritmo ni la imagen metafórica, antes prefieren incluso postular textos que carezca de ellos impulsando imágenes de contenido semiológico o abstracciones de carácter lógico. Es heterogénea, profusamente intertextual, participa de todos los discursos llegando incluso al collage y no rehuye el humor heredado de la antipoesía.

Dentro de este contexto de innovaciones y rupturas emerge La nueva novela (1977). Un texto que rechaza de entrada cualquier convención literaria conocida y que opta por reemplazar el lenguaje poético por el científico para explorar la representación de lo real. En este sentido lo que La nueva novela plantea (y que analizaremos en este artículo) es la imposibilidad de aclarar el sentido último acerca de la realidad a pesar de la exactitud del lenguaje y el conocimiento científico utilizado. Antes bien, toda pretensión de verdad o certidumbre es sustituida por una paradoja o una forma del absurdo. Esta exploración se efectúa de una manera humorísticamente deconstructiva donde las paradojas y las contradicciones alimentan esta exploración de la realidad. "Las paradojas de Martínez en este terreno recuerdan de modo inevitable otras paradojas que provienen de la física no euclidiana y de la teoría de la relatividad, sólo que llevadas a un delirante sentido del absurdo" (Galindo 35). En lo que sigue, se examinarán las estrategias textuales y epistemológicas con las cuales J.L. Martínez aborda la pregunta por la realidad: “¿Qué es la realidad? ¿Cuál es la realidad?”

En primer lugar, los distintos soportes del libro (verbales, iconográficos y objetuales) transforman la propuesta de La nueva novela en una "continuidad indisoluble entre el concepto, la palabra, la imagen y la materia misma del libro” (Daydi-Tolson 406). El libro es en sí un libro-objeto y una crítica. Una crítica tanto al lenguaje poético y sus posibilidades de expresión como al soporte del libro en cuanto objeto. Con una "humorística versión del decontructivismo", Martínez relativiza "los saberes culturales y literarios, operación de desestabilización que incluye al mismo texto” (Galindo 160). La palabra como expresión y fundamento de realidad está puesta en duda. Martínez cuestiona incluso su propia materialidad. Un libro que es "exposición del drama de lo realirreal, [...] continuidad de un lenguaje universal que se hace deshaciéndose, nominando

Revista Iberoamericana, Vol. LXXVI, Núms. 232-233 Julio-Diciembre 2010, 855-874
ISSN 0034-9631 (Impreso) 
el vacío en que la objetividad se fragmenta y reunifica, es el esfuerzo mallarmeano por mostrar el signo desencializado de su poder atributivo, desnudo" (Espinoza 4). Y, sin embargo, esta desnudez es paradójica. Una abigarrada colección de citas, guiños y homenajes críticos recorren las páginas de este libro-objeto. ${ }^{5} \mathrm{Y}$, a pesar de ello, " $\mathrm{La}$ nueva novela [...] se resiste, sin embargo, y por todos los medios técnicos y formales a una definición genérica” (Lastra-Lihn 197). Su desnudez abigarrada, su humorismo desatado y corrosivo, su lenguaje matemático, axiomático enemigo de cualquier tipo de lirismo; su impersonalidad creada por un poeta que gustada de irradiar una "identidad velada” (Rivas 55); su propuesta lúdica que oscila entre la desconstrucción y el simple placer de una exposición poética ingeniosa; su “energía de bricoleur” (Lastra-Lihn 199), fuerza combinatoria que lleva la intertextualidad hasta el agotamiento o el paroxismo; terminan, en conjunto, por no sólo "ampliar el soporte significante del texto" (Galindo 24), sino servir como multiplicadores semánticos en un texto donde los signos han perdido todo espesor y donde, probablemente, "el significante no cubra ningún significado" (Lastra-Lihn 200).

Veamos cómo opera La nueva novela y dónde radican sus formulaciones paradójicas. En primer lugar, J.L. Martínez juega con las oposiciones realidad e ilusión, existencia y no-existencia, lenguaje y silencio, materialidad y transparencia, palabra y signo, lenguaje poético versus lenguaje científico, poema y axioma, poesía y novela. Juego de oposiciones binarias que terminan por señalar las inconsistencias de la realidad visible y funcionan como "advertencias del desorden subyacente de las construcciones sofisticadas de nuestros sistemas de conocimiento” (Kirkpatrick 226). Pero, a Martínez no le interesa cualquier tipo de conocimiento sino aquel que es fundamento de realidad y cuya existencia puede ser probada por medio de operaciones racionales. Así también lo ha visto Monasterios, "La sospecha de que la realidad es un concepto problemático es precisamente el punto de partida y de llegada de La nueva novela; no en vano las nuevas actualizaciones verbales están destinadas a indagar la naturaleza de la realidad: “¿Qué es la realidad? ¿Cuál es la realidad?” (860). Como veremos más adelante,

\footnotetext{
5 Así encontramos en él a los dramaturgos Jean Tardieu y Eugene Ionesco, a poetas como Hölderlin, Nerval, Rimbaud, Baudelaire, Mallarmé, Paul Valèry, W.H. Auden, Yeats, Vicente Huidobro y los surrealistas. Los escritores Edgar Lear, Lewis Carroll y Julio Cortázar. También están Christian Morgansen, Proust, Lezama Lima y Miguel Serrano. Los proyectos político-ideológicos de Marx y Engels, los de orden filosófico como los de Blanchot, Deleuze, Guattari, Foucault y Derridá. Los de orden plástico como los de Francis Picabia y Marcel Duchamp. Los teóricos como el de Roger Callois, los postulados matemáticos de Euclides, Gauss, Lobatchewsky y Einstein. O provenientes del mundo de la cultura o la historia: Hitler, Napoleón, Yoko Ono; íconos como el de Superman, además de citas de textos, recortes de diario y fotografías.

6 "Recuérdese que la metáfora de F. Saussure para referirse a los dos constituyentes del signo (significante y significado) es el anverso y reverso de una misma lámina. El signo al que se refiere J.L.M. es un anverso que carece de reverso, y el "lenguaje vacío” es un lenguaje asemántico”. (Lastra-Lihn 200)
}

$\begin{array}{llrr}\text { ISSN 0034-9631 (Impreso) } & \text { ISSN 2154-4794 (Electrónico) }\end{array}$ 
Martínez rehuye cualquier tipo de explicación. Por tanto, "lo que llamamos realidad, se relativiza. La pretensión de racionalidad y objetividad del mundo real es puesta a prueba mediante su mismo lenguaje y llevado a un extremo a través del humor que recorre todo el libro. Sátiras, parodia, proposiciones ingeniosas no son otra cosa que una ironía contra el mismo lenguaje de La nueva novela y sus soportes. Resultado que no puede sorprender, puesto que desde el comienzo el autor nos ha anunciado su intención de ponerse en entredicho y al mismo tiempo cuestionar la idea canónica de autoría. "En un acto final de auto-negación, Juan Luis Martínez, Juan de Dios Martínez, anula toda trascendencia e individualismo que se pueda identificar en cualquier cosa que él haya creado de los trazos del saber a su alcance” (Kirkpatrick 233).

Ahora bien, de los distintos problemas que propone La nueva novela, el del lenguaje aparece como el más radical. Crítica del lenguaje, pero también elección de uno nuevo: el de la ciencia. Lenguaje y pensamiento científico resultan dos elementos impensados para la poesía. Pero este desafío -la utilización de un lenguaje tomado de las ciencias exactas- es también un regreso a lo esencial de las cosas, una búsqueda de lo real. Aquello que es verdadero orden y fundamento de mundo. La operación de Martínez va por la búsqueda de un nuevo lenguaje para dar cuenta de un problema esencialmente humano: el problema de la realidad.

Todos los errores de las llamadas ciencias «exactas» proceden del hecho de que la mentalidad que sustenta estas ciencias tiende a prescindir de la existencia del sujeto humano, que, pese a todo, es el espejo en el que el fenómeno del mundo se revela. El referir toda observación a fórmulas matemáticas permite hacer abstracción en una larga medida de la existencia de un sujeto conocedor, y comportarse como si sólo existiera una realidad «objetiva»; se olvida deliberadamente que ese sujeto, precisamente, es la única garantía de la constante lógica del mundo; y que ese sujeto, a quien no debe entenderse sólo en su naturaleza relativa al yo, sino, antes bien, en su esencia espiritual, es el único testimonio de toda la realidad objetiva. (Burkhardt 121)

Para Martínez, el lenguaje poético convencional se ha agotado y con ello todas las ideas canónicas asociadas a quienes hacían uso de este tipo lenguaje. De ahí el reemplazo del verso tradicional por el proposición matemática. ${ }^{7}$ Como Platón, Martínez expulsa a los poetas de la República cansado de los excesos del lirismo y las "grandes personalidades poéticas”. Martínez percibió claramente

7 En lógica simbólica, una proposición se refiere a un enunciado que puede ser sujeto a los juicios de verdad o falsedad. Para Juan Luis Martínez, el conjunto de estas proposiciones constituye el lenguaje de La nueva novela. Martínez coincide en este punto con Wittgenstein quien plantea la misma idea de una manera más general en el aforismo 4 del Tractatus: “El lenguaje es la proposición con significado” (32).

Revista Iberoamericana, Vol. LXXVI, Núms. 232-233 Julio-Diciembre 2010, 855-874 
el hastío y la saturación que por entonces provocaba el Yo lírico con sus excesos verbales y existenciales. [...] El camino de La nueva novela hacia la impersonalidad de la poesía y la virtual eliminación del autor fue otro: disolver el Ego poético - poeticoide-en favor del lenguaje radicalmente objetivo de los axiomas físico-matemáticos. (Valente 1)

Sin embargo, la impersonalidad de la voz de Martínez (si esta voz existe) en $L a$ nueva novela es engañosa. Su pretendida objetividad científica esconde casi siempre la enunciación de preguntas que no pueden responderse o desemboca en paradojas y humoradas. Es una voz que se ríe de lo que enuncia, "nuestro guía narrativo inventa e improvisa sin perder jamás su aire autoritario, aún cuando entra en el territorio del ridículo" (Kirkpatrick 229). La ausencia de una voz única en La nueva novela es, sin embargo, una presencia plural. Este sujeto ausente, esa presencia velada, es todos y es nadie. El mérito del trabajo de Juan Luis Martínez radica en el haber descubierto que un lenguaje, el más objetivo e impersonal, el de las ciencias matemáticas, podía dar cuenta que lo subjetivo deja de serlo frente a lo que es fundamento de realidad. ${ }^{8}$ Ahora bien, si entendemos el problema del fundamento como la pregunta que nos interroga "de qué verdad es posible hablar, qué término es la palabra realidad, qué camino es el camino si la huella es borrada históricamente por miles y miles de explicaciones y todas parecen llevar al abismo” (Espinoza 3), entonces Juan Luis Martínez no hace más que preguntarse por el ser de las cosas. Y esta tarea, como ha visto Heidegger con fina lucidez, la de "liberar al lenguaje de la gramática para ganar un orden esencial más originario es algo reservado al pensar y poetizar” (Carta 100). Por esta razón, La nueva novela es la obra de un poeta, porque no importa cual sea el lenguaje o la estructura que se use, ni la presencia o ausencia del autor, su accionar nunca escapa a lo propio de la poesía o del pensar.

Otro elemento que se formula paradójicamente es la disposición de los capítulos del libro. En una primera lectura, el índice nos revela una estructura, un orden. Siete capítulos, una sección de notas y referencias, además de un epígrafe, postulan una serie de ejercicios o "tareas por resolver” (de la índole más diversa) que no presentan ninguna forma de aproximarse a las posibles respuestas. El caos y la paradoja que subyacen en este trabajo -a pesar de la ilusión de estar frente a un "libro de texto" — tienen el mismo efecto que el que esconde la realidad bajo su aparente pretensión de orden. Accionar paradójico que se impone desde la portada, ${ }^{9}$ y que contiene y anticipa muchos de los temas del libro. Una fotografía en blanco y negro de un grupo de casas que parecen

8 La elección del lenguaje científico le permite a Juan Luis Martínez utilizar un lenguaje donde la ausencia del yo y el antilirismo se combinan en un lenguaje impersonal y neutro. “Además, el científico mientras escribe ciencia puede hacerlo de una manera que nunca podría hacerlo en un trabajo literario convencional porque en esos textos usa palabras científicas que son emocionalmente neutras”. (Savory 121).

9 “[...] la portada de su libro: una casa viniéndose abajo, imagen que [Juan Luis Martínez] encontró en un diario que informaba acerca de un terremoto en Alaska”. (Joannon 20)

ISSN 0034-9631 (Impreso) 
estar cayéndose apuntan a desestabilizar unos de los símbolos básicos de la vida y la convivencia humana: la casa. Ahora sitio inestable y peligroso, no puede ofrecerse ya como albergue o protección. En la página 121, tres citas amplían el contenido semántico de la portada (la cual ha sido reproducida en la página 120).

\title{
NOTA 1. LA DESAPARICIÓN DE UNA FAMILA Véase: EPÍGRAFE PARA UN LIBRO CONDENADO*
}

\author{
“La casa que construirás mañana, ya está en el pasado y no existe”. \\ Anónimo \\ "El hombre nace en la casa, pero muere en el desierto". \\ Proverbio del Gran Lama Errante \\ oído por S.J. Perse en el desierto de Gobi
}

“Cuando la familia está hecha viene la dispersión; cuando la casa está construida, llega la muerte”. José Lezama Lima

* Véase: Adolf Hitler Vs. Tania Savich (EL DESORDEN DE LOS SENTIDOS)

La casa es el lugar de las desapariciones. La casa del mañana ya pertenece al pasado y no existe. "La casa es el mundo como lugar abierto, desprotegido y amenazante, que en lugar de sustraer los peligros de la existencia los condensa y especializa, señalándole a cada uno el modo y el lugar específicos de su desaparición.” (Lastra-Lihn 199). Sobre la fotografía de la portada, dos nombres aparecen entre paréntesis y tachados, (JAN EUIS MARTÍNEZ), (JUAN DE DIOS MARTINEZ). Ambos dudosos. La autoría queda, de este modo, cuestionada doblemente. Paréntesis y tachaduras quieren ser un problema y un énfasis de la desaparición voluntaria del autor del texto. "En un acto final de auto-negación, Juan Luis Martínez, Juan de Dios Martínez anula toda trascendencia e individualismo que se puede identificar en cualquier cosa que haya "creado" de los trazos del saber a su alcance" (Kirkpatrick 233). Como ha visto Roland Barthes en "La muerte del autor", el texto moderno ahora se produce y se lee de tal manera que el autor se ausenta de él en todos los niveles. Tal es el caso de La nueva novela. "es el lenguaje el que habla, no el autor; escribir, es, consiste en alcanzar, a través de una previa impersonalidad [...], ese punto en el cual sólo el lenguaje actúa, «se realiza», y no «yo»" (143). A lo anterior, se suma el problema del título, La nueva novela que busca en la paradoja postular un género impreciso o "agenérico", como lo han visto Pedro Lastra y Enrique Linh (198). De esta manera, la escritura de La nueva novela se postula como abierta, múltiple e infinita. "Una vez eliminado el Autor, se vuelve inútil la pretensión de «descifrar» un texto. Darle un Autor a un texto es imponerle un límite a ese texto,

Revista Iberoamericana, Vol. LXXVI, Núms. 232-233 Julio-Diciembre 2010, 855-874
ISSN 0034-9631 (Impreso) 
proveerlo de un significado último, cerrar la escritura” (Barthes 147). Al desaparecer el autor desaparecen las certezas hermenéuticas respecto del texto. El autor moderno no puede exceder al texto, su gesto ya no es el de la expresión, sino el de la inscripción. En este sentido, La nueva novela -a través de la multiplicidad de sus escrituras- excede a su autor de tal manera que termina por devorarlo y denunciar la imposibilidad de una autoría original. Como ha señalado el mismo Barthes, es imposible pretender, en un texto de esta naturaleza, un sentido último, final. De ahí que la tachadura del nombre del poeta sea una estrategia para hacerlo desaparecer como autor.

En la multiplicidad de la escritura, todo está por desenredarse, pero nada por descifrar; puede seguirse la estructura, [...] en todos puntos, en todos sus niveles, pero no hay nada debajo; el espacio de la escritura ha de recorrerse, no puede atravesarse; la escritura instaura sentido sin cesar, pero siempre acaba por evaporarlo: procede como si fuera una exención sistemática del sentido. (147)

Este motivo -el de las desapariciones- que aparece con insistencia en el texto, guarda una profunda correspondencia como temática con muchos textos o fragmentos de textos de La nueva novela. En el lomo del libro nos encontramos a un pequeño foxterrier que resulta ser el guardián del libro. Su nombre es Sogol (anagrama de LOGOS) y que está encerrado en un círculo, lugar de todas las desapariciones.

Dependiendo del énfasis que se le otorgue, LOGOS puede ser interpretado en el sentido heraclitano (principio abstracto universal que genera un orden cuyo conocimiento conduciría a la sabiduría); en el sentido judaico (LOGOS es aquí una realidad concreta: dios mismo, el camino, la verdad y la vida) o, finalmente, en el sentido lógico (razón encaminada hacia una pretensión de verdad). (Monasterios 864)

Esta relación entre SOGOL (o LOGOS) y las desapariciones se expone, mediante el recurso de imágenes expuestas en su anverso y reverso, en el capítulo V. En la página 81, "FOX TERRIER DESAPARECE EN LA INTERSECCIÓN DE LAS AVENIDAS GAUSS Y LOBATCHEWSKY”. Y en la página 83, "FOX TERRIER NO DESAPARECIDO NO REAPARECE EN LA NO-INTERSECCIÓN DE LAS AVENIDAS (GAUSSY LOBATCHEWSKY)”. El mismo fox terrier también desparece en "La desaparición de una familia":

Antes de que "Sogol”, su pequeño fox terrier desapareciera en el séptimo peldaño de la escalera hacia el 2 piso él le había dicho: “-Cuidado viejo camarada mío, por las ventanas de esta casa entra el tiempo, por las puertas sale el espacio; al menor descuido ya no escucharás las señales de ruta y de esta vida, habrás perdido toda esperanza. (137)

\footnotetext{
Revista Iberoamericana, Vol. LXXVI, Núms. 232-233 Julio-Diciembre 2010, 855-874
ISSN 0034-9631 (Impreso)
} 
Casa, desapariciones y una imagen de concepto de logos, se combinan aquí para nuevamente indicar la inestabilidad de lo real. No es claro cuál es el LOGOS que desaparece y cuál es el que permanece, es "el principio que se extingue" (Monasterios 865). Lo cierto es que el logos de Heráclito, el orden que es unidad y medida. Una correspondencia que resulta especialmente ilustrativa en este contexto es la planteada en "La desaparición de una familia" (137). Si la casa resulta, por definición y como ya habíamos visto anteriormente, ${ }^{10}$ un espacio inseguro o peligroso, en este texto la idea cobra especial dramatismo, al desaparecer no sólo los integrantes de la familia (incluida la voz que habla en el poema), sino que además “toda esperanza” (137). Como ha sido señalado muy bien Monasterios, "A propósito de 'La desaparición de una familia' cobran intensidad una serie de composiciones anteriores, a las que volvemos desde otra perspectiva” (863). En especial, la Nota 1, antes indicada, que están en directa correspondencia con "La desaparición de una familia". Del mismo modo lo hacen los textos de las páginas 116, "EL CÍRCULO DE LA SOLEDAD. EL ESTRECHO CÍRCULO DE LA SOLEDAD”; la versión en negativo de la página 116 dispuesta en la página 117, la página 114, "Tania Savich y la fenomenología de lo redondo"; 132, "NOTA 11. ADOLF HITLER VS, TANIA SAVICH I. Véase: EL DESORDEN DE LOS SENTIDOS”; 133, "NOTA 12. ADOLF HITLER VS, TANIA SAVICH II. Véase: NOTAS Y REFERENCIAS” (Nota 11). Juegos de referencias cruzadas que alimentan y enriquecen los significados aparentemente dispersos de $L a$ nueva novela. "La obra de Juan Luis Martínez reclama permanentemente su más allá. Los textos invertidos reclaman su complementario espejo. El libro se prolonga en los espejos reales y estos reflejos se prolongan en los espejos ficticios” (Merino 2). Del mismo modo, la contraportada también se inscribe en este juego de espejos. Martínez vuelve a sus "tareas por resolver" al pedirle al lector que, sobre un dibujo cuadriculado de 48*36=1728 cuadrados, "Dibuje el contorno de cada cuarto incluyendo puertas y ventanas. Marque dos rutas de escape para cada miembro de la familia”. Sin embargo, la misma contraportada se ha anticipado en la página 136, la cual aparece reproducida exactamente como aparece en la contraportada, pero esta vez se le ha agregado el dibujo de una liebre en el extremo inferior derecho. Es la liebre de marzo que aparece en Alicia en el país de las maravillas. Otra referencia intertextual que nos demuestra que, "Tanto Carroll como Martínez dislocaron el fantasma de la realidad mediante complejos juegos del intelecto. Carroll lo hizo amparándose en la lógica, Martínez recurrió a una infinidad de referencias culturales" (Joannon 19).

Otro juego de espejos está dado por las solapas del libro. Estrategia de escritura que busca ser un manual de orientación para la lectura del libro-objeto. Martínez los utiliza, en conjunto con la portada y la contratapa, como formas de pesquisar algunos

$\overline{10}$ Ver nota 1. LA DESAPARICIÓN DE UNA FAMILA.

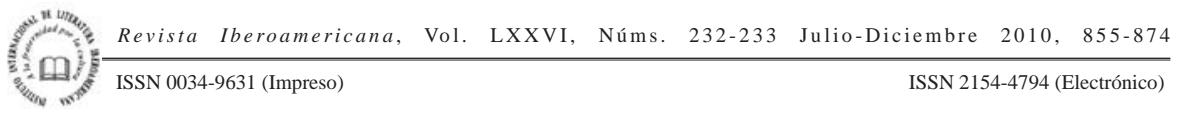


rasgos que funcionan como expectativas de recepción” (Merino Las expectativas 332). Son, estos textos, además un replanteamiento crítico de la función que tradicionalmente cumplen las solapas: espacios tradicionalmente dedicados a información suplementaria. En La nueva novela "son en cambio parte integral del texto de Martínez" (Daydi-Tolson 408). Dos textos las ocupan: La Realidad I y La Realidad II. Ambos se proponen a sí mismos como ideas centrales del libro-objeto de Martínez: "el cuestionamiento mismo de la realidad y lo que será el comienzo de una lógica absurda y de una mirada y un pensamiento que se afirma y niega a la vez" (Valdivieso 56). Los dos textos son casi idénticos, pero "entre la realidad primera y la segunda hay una gran diferencia: son antitéticas” (Daydi-Tolson 409). El punto en común está dado por la siguiente línea, "Lo real es sólo la base, pero es la base”. Pero, mientras el primer texto afirmará, "Lo real es aquello que te chocará como realmente absurdo"; el segundo dirá, "Lo real es aquello que se espera de cada uno de nosotros". Del mismo modo, en la solapa de la portada encontramos la siguiente afirmación, "El ser humano no soporta mucha realidad"; en la solapa de la contraportada el texto dirá, "Nada es bastante real para un fantasma". Ideas que se resumen al final de cada uno de los textos escritos en la solapas. En el primero, "Nada es real”; en el segundo, “Todo es real”. Este par antitético vuelve sobre el tema de la deconstrucción del Logos que podría esbozarse también de la siguiente manera, "Nada es real y todo es real" ${ }^{11}$ En la NOTA 4 de la página 125, aparece una imagen de una parte del collar de Sogol, que lleva la siguiente leyenda entre paréntesis (DESCONSTRUCCIÓN DEL LOGOS). Bajo ella hay una cita de Mallarmé, "Mi Obra es un callejón sin salida”, que bien podría ser el epígrafe de La nueva novela.

Todo este juego de paradojas y de preguntas que no tienen respuestas (ya sea porque todas las respuestas son plausibles o porque ninguna respuesta es posible) llevan a Martínez a un callejón sin salida. Pero este atolladero es otro espejismo. Primero, "Uno de los elementos que llama la atención en La nueva novela es su capacidad para ampliar el soporte significante del texto" (Galindo 24). El libro funciona como un multiplicador semántico. Segundo, está multiplicación puede ser infinita o, al menos, interminable, "Una y otra vez La nueva novela regresa inexorablemente a la noción irreductible de la insuficiencia” (Kirkpatrick 233). Tercero, no es función del poeta esbozar respuestas. Al contrario, como se ha visto más arriba, tanto el autor como las posibles interpretaciones del texto se plantean inicialmente para lector como imposibles de descifrar. La nueva

11 "La misma nota es un claro ejemplo de deconstrucción del logos, entendido como palabra, discurso, sentido. Este quiebre del orden, este “desorden de los sentidos” de la nota es extensible a todo el texto de La nueva novela”. (Monarca 55). Además, es posible agregar que "La “deconstrucción del logos” invita a romper con el modo convencional de pensar, considerando que desde comienzos del filosofar existe -con variaciones a través de los siglos- una conexión indisoluble entre el ser, como tema propio y específico de la filosofía, y el logos, como la reunión de todo ente, que viene reproducida en el pensar humano, en cuanto que este mismo ordena al ente a su esencia en el ser y lo traduce al lenguaje” (Müller y Halder 277-8).

Revista Iberoamericana, Vol. LXXVI, Núms. 232-233 Julio-Diciembre 2010, 855-874
ISSN 2154-4794 (Electrónico) 
novela apunta, para su completa interpretación, a un súper-lector, un lector hipotético, ideal, capaz de la hermenéutica del texto completo. Como ha visto Wolfgang Iser, “el lector ideal, entonces, debe no sólo completar el significado potencial del texto independientemente de su propia situación histórica, sino que además debe hacer esto exhaustivamente” (29). Propuesta imposible que, en su postulación de un lector ideal que agota el texto en su lectura, permite hacer de La nueva novela un texto “incompleto" o “indeterminado". El "lector ideal” se convierte entonces en un sujeto que debe, en la dialéctica texto-lector, completar el o los significados del texto de una manera activa. ${ }^{12}$ Como ha señalado Roman Ingarden, se trata de un lector co-creador cuya espacio interpretativo está delimitado por la obra misma. "La función del lector consiste en prestarse a las sugerencias y directivas que emanan de la obra, actualizando, no cualquier aspecto que escogiera, sino aquellos sugeridos por la obra misma” (80). La dificultad de la lectura de La nueva novela radica precisamente en esta extraña libertad, la de ser un espacio indeterminado semánticamente donde confluyen diversos y contradictorios discursos, pero que no pueden reclamar un significado ni un autor estable y único. ${ }^{13}$ La nueva novela es así una plataforma interpretativa que invita a un lector competente a un juego interminable cuya autor no asume ninguna responsabilidad hermenéutica.

Dentro de este contexto -donde las operaciones deconstructivas del texto se extienden a "todos los campos en los cuales el lenguaje fragiliza los criterios de verdad y de realidad, por encima de la presunción de verosimilitud” (Lastra 198). Una de las metáforas más poderosas utilizadas por Martínez es la del espacio no-euclidiano. Aquí el lenguaje científico se conjuga, en esta búsqueda de lo real, con las indagaciones de la ciencia. "Porque a todo enunciado, científico o filosófico, referido a lo real, es inherente un modo de trascender el aquí y el ahora del hecho empírico; porque tanto la ciencia como la filosofía recurren a un mismo estilo (en un mismo sentido, al menos) toda vez que procuran ejercitar distinciones en el seno de aquello que llamamos experiencia” (Estrella 58). Volvemos inexorablemente sobre las interrogantes planteadas en un comienzo: ¿Qué es la realidad? ¿Cuál es la realidad? Pero ahora Juan Luis Martínez haciendo uso del lenguaje matemático hace una indagación de la realidad de orden metafísico. ${ }^{14}$ "En suma, la lógica y la matemática establecen contacto con la realidad a

${ }_{12}$ Un tipo de lector ideal, por ejemplo, puede ser el lector informado propuesto por Stanley Fish. "El lector informado es alguien que 1.) está en completa posesión del "conocimiento semántico que un lector maduro aporta a la tarea de la comprensión”. Esto incluye conocimiento (vale decir, experiencia, tanto como productor como interpretador) de conjuntos léxicos, probabilidades de ubicación, idiomas... otros dialectos, etc. [...] 3.) tiene además competencia literaria [...]. (Fish 145).

13 "La tarea del arte no es tanto darse por informado del mundo como crear un complemento para ese mundo, [...]. En este sentido la literatura (y lo mismo debe ciertamente aplicarse a todo tipo de mensajes artísticos) sería determinar la denotación de un objeto indeterminado". (Eco 46).

${ }^{14}$ Me refiero específicamente a los textos de las páginas 80, 81, 82 y 83 mencionadas más arriba; la página 112, "PRIMERAS INVESTIGACIONES SOBRE LAS BURBUJAS EN LA SUPERFICIE DEL CAFÉ

\footnotetext{
Revista Iberoamericana, Vol. LXXVI, Núms. 232-233 Julio-Diciembre 2010, 855-874 ISSN 0034-9631 (Impreso) 
través del puente el lenguaje, tanto el ordinario como el científico” (Bunge 15). Veamos, entonces, dos ejemplos que ilustran lo que hemos venido diciendo hasta ahora. A través del lenguaje matemático y el conocimiento científico, Martínez, en el siguiente par de textos, vuelve a plantear la naturaleza paradójica de la realidad y a demostrar que aunque se utilice un lenguaje proveniente de las ciencias exactas, no hay posibilidad de dar una respuesta última acerca de la verdadera naturaleza de lo real. Un problema por cierto epistemológico que en La nueva novela es tratado desde la geometría no euclidiana y la termodinámica respectivamente.

En el primer texto, "FOX TERRIER DESAPARECE EN LA INTERSECCION DE LAS AVENIDAS GAUSS Y LOBATCHEWSKI” (81), Martínez replantea uno de los problemas más antiguos y complejos de la historia de la Geometría: la discusión del Quinto Postulado de Euclides (330 a.C.-275 a.C.). Veintiún siglos tardaron los matemáticos en resolver este problema. En su formulación más sencilla dice: "Por dos puntos distintos pasa una única recta”. Esto significa que si dos rectas coinciden en dos puntos distintos ambas rectas son iguales. Por lo tanto, dos rectas distintas pueden tener sólo un punto en común o ninguno. En esteúltimo caso se dicen paralelas. La imposibilidad de demostrar este axioma a partir de los cuatro axiomas anteriores de Euclides hizo suponer a muchos matemáticos que el postulado era falso o independiente de los otros. ${ }^{15}$

CONTENIDO EN UNA TAZA"; y la 115, "NUEVAS INVESTIGACIONES SOBRE LAS BURBUJAS EN LA SUPERFICIE DEL CAFÉ CONTENIDO EN UNA TAZA".

${ }^{15}$ Existen tres tipos de geometrías que surgen a partir del V postulado de Euclides. Si se acepta que "por un punto exterior a una recta pasa una y sólo una recta paralela a ella", estamos frente a la geometría euclidiana, que es la que aprendemos en el colegio secundario. Si se lo niega hay dos opciones. La primera es: "Por un punto exterior a una recta pasan infinitas rectas paralelas a ella", en este caso estamos frente a la geometría no euclidiana llamada hiperbólica. Ejemplo de ello es la gráfica de la silla de montar. Y la segunda, "Por un punto exterior a una recta no pasa ninguna recta paralela a ella". En ese caso estamos frente a la geometría no euclidiana llamada elíptica donde sus rectas son rectas cerradas llamadas geodésicas. Ej. la elipsoide.

Ejemplo de la silla de montar:
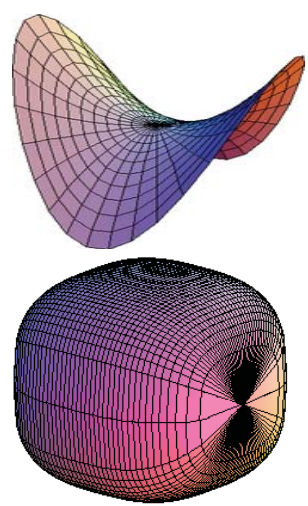

Ejemplo de elipsoide:

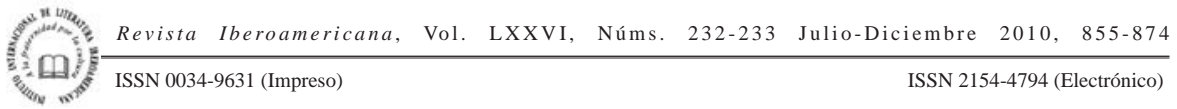


El matemático alemán Karl F. Gauss (1777-1855) fue probablemente el primero en creer en la independencia de éste al aceptar la posibilidad lógica de que existiera una geometría en la cual se negara este postulado. Llegó a demostrar la independencia del $\mathrm{V}$ postulado, pero por temor a contravenir las creencias de la época nunca publicó los resultados de sus investigaciones. ${ }^{16}$ Aún así, logró anticipar la geometría no euclidiana. Por otra parte, el matemático ruso Nicolai I. Lobatchewski (1793-1856) dio un paso gigantesco al preguntarse si dicho axioma era completamente imprescindible para construir una geometría. Desarrolló una nueva geometría, denominada no euclídea, ${ }^{17}$ partiendo de que por un punto no contenido en una recta pueden trazarse al menos dos rectas paralelas a la recta dada. Sus ideas se publicaron 1829. Tres cuartos de siglo después, Einstein pudo demostrar que la estructura del universo no era euclídea y que los conceptos teóricos propuestos por Lobatchewski tenían aplicación en el desarrollo de la Teoría General de la Relatividad.

Ahora lo que nos importa aquí es que una figura representada en uno de los dos espacio no puede ser vista en el otro, sin embargo ambos espacios pueden tener uno o varios puntos de intersección "such as at the intersection of Gauss and Lobatchewsky Avenues. This point becomes the intersection of existence and non existence" (Jackson 136). ${ }^{18}$ Por esa razón a Martínez le interesan los límites entre ambos espacios mas que los espacios en sí mismos, "esa fisura precisa e infinitesimal" ${ }^{19}$ que "pertenece a las geometrías no euclidianas” (81). Por ello, en el texto de la página 81, cuando el Fox Terrier SOGOL (o Logos) se pierde en la intersección de ambas avenidas, su situación es descrita caracterizando, al mismo tiempo, la relación de límite entre ambos espacios. De este modo, un problema, puramente geométrico, se transforma en una reflexión en torno a la representación matemática de la realidad y a la composición real del universo. Veamos la relación dialógica entre poesía y matemáticas que se explicita en algunos de los párrafos del texto de la página 81:

1.

a. La avenida Gauss sólo es invisible en su punto de intersección con al avenida Lobatchewsky

${ }^{16}$ Por esta razón, Martínez lo considera en La nueva novela un matemático euclidiano.

${ }_{17}$ Básicamente, el espacio euclidiano es el espacio sensible que tiene alto, largo y ancho. Es un espacio plano. Por otra parte, el espacio no euclidiano es curvo donde ocurren cosas muy diferentes a lo normal; por ejemplo, puede que la línea más corta entre dos puntos sea una curva (y no una recta, como en el espacio plano). Puede que dos paralelas se corten en un punto o en infinitos puntos.

18 Aunque habría que señalar que los términos "existencia” y "no existencia” no son pertinentes a esta discusión. Lo que señala la intersección de ambas avenidas son dos formas distintas de representación de la realidad y no dos estados antagónicos que se contradicen mutuamente. Sogol ha desaparecido, pero esto no quiere decir que haya dejado de existir.

${ }_{19}$ El equivalente matemático del vocablo fisuras en un espacio, ya sea euclidiano o no, es "singularidades”.

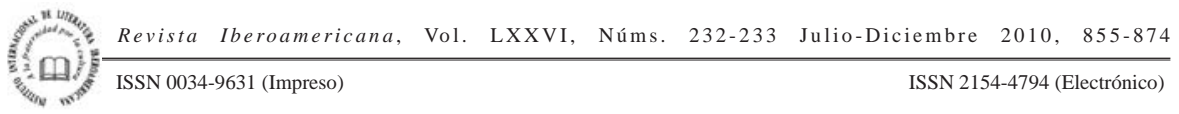


b. La avenida Lobatchewsky sólo es visible en su punto de intersección con la avenida Gauss

2.

a. Que las avenidas Gauss y Lobatchewsky sean invisibles en uno u otro punto de sí mismas, no significa que el Fox terrier no sea visible en cualquier punto de ambas avenidas.

Finalmente,

[...]

b. Dado que esa figura precisa e infinitisemal pertenece a las geometrías no euclidianas la única solución es que el Fox Terrier regrese por su propios medios desde esa otra dimensión, cuya entrada y salida se encuentran en la intersección de las avenidas Gauss y Lobatchewsky.

Una ampliación de esta idea es puesta en práctica en el segundo texto: "PRIMERAS INVESTIGACIONES SOBRE LAS BURBUJAS EN LA SUPERFICIE DEL CAFÉ CONTENIDOENUNATAZA”(112).Aquí el concepto geométrico-matemático que rige el comportamiento de las burbujas en una taza de café obedece al mismo comportamiento de las líneas en la geometría no euclidiana, las cuales nunca componen una frontera. ${ }^{20}$ “Otro aspecto del espacio de Lobatchewski que Martínez quiere que entendamos es su curvatura. Mientras en el espacio euclidiano las líneas rectas se extienden indefinidamente en cualquier dirección, estas mismas líneas (geodésicas) cuando son trazadas en un mapa desde el espacio de Lobatchewski al euclidiano aparecen curvadas” (Jackson 136-7). Así, en el texto de Martínez, las burbujas, en un espacio no euclidiano, están condenadas a habitar la superficie de la figura que forma el café, la taza y las burbujas. Veamos parte del texto:

1. Las burbujas que forman en la superficie del café contenido en una taza, no se mantienen nunca en el punto céntrico de la superficie, sino que agrupan en las paredes de la taza.

2. Como las burbujas carecen de Noción de infinito, es imposible que permanezcan en el punto céntrico de la superficie. [...] (112)

La “Noción de Infinito” que postula Martínez para las burbujas es, ciertamente,

20 "Hasta donde podemos saber, no existen fronteras en el espacio tiempo (salvo en puntos aislados), lo que no quiere decir que sea infinito en extensión” (Rago 66).

Revista Iberoamericana, Vol. LXXVI, Núms. 232-233 Julio-Diciembre 2010, 855-874
ISSN 2154-4794 (Electrónico) 
una ironía. Los puntos o las burbujas que componen este espacio no pueden aspirar a formas figuras geométricas infinitas. Martínez escribe, "Es por esta razón, que una burbuja sacada de la superficie del café y puesta fuera de la taza, desaparece” (112). La conclusión es obvia, tal "fuera de la taza” no existe en el mismo plano en que está la taza y el café. Esa o esas burbujas desaparecerán, obviamente, en el cruce de las avenidas Gauss y Lobatchewsky, de la misma manera que desapareció Sogol. Más adelante, Martínez agrega:

3. Mientras una burbuja se mantuviere en el centro de la superficie del café contenido en la taza, será una burbuja centro con posibilidades de Infinito y personalidad. Desde el instante que esta burbuja deja de ser centro y comienza su viaje hacia la pared de la taza, se despersonaliza y pierde momentáneamente sus posibilidades. (Martínez 112)

Aquí nos encontramos con una asociación provocadora que emerge desde la ciencia, pero que reviste ciertas implicaciones filosóficas y religiosas. Dentro de este contexto irónico, la ausencia de noción de infinito es un "impedimento para poseer una personalidad”. Las burbujas sólo recuperarán su personalidad una vez que se integren al Infinito. Dos notas a pie de página revelan el juego: dimensión matemática versus dimensión humana. Las notas dicen así: "Por oposición, un hombre será o deberá ser siempre el centro del infinito”, "Puesta en la dimensión humana, la pared de la taza sería sólo un muro virtual de contención” (112). Extraña confianza en el ser humano se desprende de este texto que no parece ser consistente, en una primera lectura, con el tono impersonal del resto del texto. Si la burbuja "es obligada a pasar a ser parte del virtual muro de contención que la limita”; un hombre, por otra parte, puesto en ese mismo lugar no podría ser contenido en los límites definidos por ese espacio, aspiraría necesariamente a la individualidad y a lo infinito, dado que podría, en primer lugar, poseer la Noción de Infinito. Pero, además, podría situarse en "el centro” de la taza de café. Ahora bien, si estas burbujas son integradas al Infinito ya no están en ningún espacio y sólo pueden desaparecer "en el instante en que se detenga todos los procesos de la naturaleza “entropía máxima” (PROCESOS IRREVERSIBLES según la Segunda Ley de la Termodinámica ${ }^{21}$ ) (115). Esto es, cuando exista un equilibrio entre todas las temperaturas y presiones, llegará la muerte térmica del Universo (Teorema de Clausius). Toda la energía se encontrará en forma de calor y no podrán darse transformaciones

21 La Segunda Ley de la Termodinámica plantea que la entropía de un sistema aumenta a medida que aumenta el desorden. La tendencia hacia un aumento del desorden es una tendencia hacia un aumento de entropía. Por tanto, la entropía de un sistema aislado aumenta a medida que éste se aproxima a su macroestado de equilibrio (el de mayor desorden). Esto significa que el incremento de entropía en un sistema es siempre mayor o igual que cero, vale decir, es siempre positivo, lo que significa que el sistema siempre tiende hacia el desorden. Y ésta, es la dirección natural en la que fluye el tiempo.

Revista Iberoamericana, Vol. LXXVI, Núms. 232-233 Julio-Diciembre 2010, 855-874
ISSN 2154-4794 (Electrónico) 
energéticas. El texto pareciera decir que sólo aquello que se integra al infinito puede morir.22

Más aún, estas burbujas no existen como entes aislados. Una vez en la taza se deben entender como entidades regidas por el espacio-tiempo y no por ambas variables por separado. Martínez parafrasea el concepto espacio-tiempo desarrollado por Einstein a través de la Teoría General de la Relatividad, en 1905, de una manera poético-matemática.

3. EL ESPACIO de cada burbuja no tiene realidad objetiva, excepto como relación entre el objeto-taza y el objeto-café que percibimos.

EL TIEMPO de cada burbuja no tiene tampoco existencia aparte del conjunto de hechos que empleamos para medirlo. (115)

¿Ciencia y poesía? Probablemente ninguna de las dos. La nueva novela efectúa a través del lenguaje y el conocimiento científico una indagación de la realidad de orden poético-filosófico. A Martínez le interesa poner en entredicho la naturaleza paradójica e incierta de la realidad. El texto en sí es contradictorio e inestable como la realidad que busca examinar. A partir de la física subatómica y la Teoría de la Relatividad sabemos que no hay una sola realidad y que todo "conocimiento científico, por oposición a la sabiduría revelada, es esencialmente falible, esto es, susceptible de ser parcial o aún totalmente refutado" (Bunge 62). Como hemos venido diciendo, La nueva novela se alimenta de la paradoja y su apropiación de las herramientas de la ciencia no la exime de ser una obra paradojal en sí misma, indescifrable y, tal vez, infinita. Y no puede ser de otro modo, la ciencia como cualquier otra disciplina del conocimiento humano ha hecho, desde el siglo pasado, confesión pública de falibilidad. "Las proposiciones matemáticas, en cuanto tienen que ver con la realidad, no son ciertas; y en cuanto que son ciertas, no tienen nada que ver con la realidad” (Einstein 87). Yendo un poco más lejos, Wittgenstein postuló no sólo lo anterior, sino la inutilidad de toda respuesta al problema científico. En el aforismo 6.52 del Tractatus Logico-Philosophicus, escribe: "Nosotros sentimos que incluso si las posibles cuestiones científicas pudieran responderse, el problema de nuestra vida no habría sido más penetrado. Desde luego que no queda ya ninguna pregunta y precisamente ésta es la respuesta" (103). Pero, lo que aquí importa no es el destino, sino el recorrido. Desde esa perspectiva, La nueva novela es una ruptura y un regreso. Rompe con las formas anteriores del lenguaje poético, demasiadas confabuladas éstas con la ilusión de la realidad, y le devuelve a la poesía su capacidad para pensar el mundo en su fundamento último de sentido. Dicho de otro modo, la poesía regresa al pensamiento y al poetizar a través de la ciencia moderna. "La tarea del pensar consistiría,

${ }^{22}$ Aunque el texto dice “desparecer,” la palabra exacta, siguiendo el principio de máxima entropía, es morir. En ese momento las burbujas desaparecería por efecto de la muerte térmica del Universo, o sea, que desaparecería junto con el Universo.

$\begin{array}{llllll}\text { ISSN 0034-9631 (Impreso) } & \text { ISSN 2154-4794 (Electrónico) }\end{array}$ 
entonces, en el abandono del pensar anterior, para determinar lo que es la «cosa» del pensar" (Heidegger Ser y Tiempo 356). Y "esta cosa del pensar" no es otra que el ser, ser que ha sido, desde Platón, siempre propiedad del logos filosófico. Y, sin embargo, “¿No es el ser la razón primera de logos poético y logos filosófico?” ${ }^{23}$ (Bravo 123).

Hasta aquí hemos revisado sólo uno de los aspectos de La nueva novela, el uso del lenguaje y el pensamiento físico-matemático. Pero, como ya he indicado al comienzo de este trabajo, el texto de Martínez tiene muchas más dimensiones, temas, propuestas y desafíos. Aquí nos hemos limitado a revisar algunos de esos aspectos y cómo se relacionan con el tema que nos ocupa en este trabajo. Su obra inagotable y plural nos recuerda lo dicho por Octavio Paz acerca de Marcel Duchamp (artista con el cual J.L. Martínez guarda más de una similitud): "El valor de un cuadro, de un poema o cualquier creación se mide por los signos que nos revela y la posibilidad de combinarlos que contiene. Una obra es una máquina de significar” (186). Y La nueva novela es eso, una máquina multiplicadora de significados, pero también de incertidumbres. Sin un centro fijo, $L a$ nueva novela rompe con el canon tradicional que postulaba la unidad como totalidad, es una obra inorgánica ${ }^{24}$ (y en esto es heredera de la vanguardia), descentrada, donde confluyen discursos diversos y también antagónicos, heterogénea, verbal, pero también plástica y hasta objetual. A pesar de su radical apuesta, el texto de Martínez es un texto neovanguardista como se apuntó al comienzo, posmoderno, y no heredero directo de la vanguardia como podría pensarse a primera vista. Martínez no cumple con el precepto que Peter Bürger plantea como fundamental para caracterizar cualquier movimiento vanguardista: "La vanguardia aparece, pues, como una instancia autocrítica, no tanto del arte como de la estructura social en la que se da; no una crítica inmanente al sistema, que actuaría en el seno de la institución, sino autocrítica de la institución del arte en su totalidad” (Bürger 23). Al contrario, Martínez no quiere ir contra la institución del arte ni devolverle al arte su praxis vital, no busca denunciar la realidad ni se compromete con ideología alguna. Tiene en común con la vanguardia histórica, por supuesto, que

${ }^{23}$ Antecedentes de una reunión de ambos logos se encuentran en los románticos alemanes, en Nietzsche y, por supuesto, en Heidegger. En el reino de la razón, filosofía y poesía profundizan su enemistad, y no será sino con la crítica y la negación de "la verdad revelada", con el intenso proceso de desconstrucción categorial que se inicia con Nietzsche e Heidegger, y que en Derridá tendrá uno de sus más extremos y extraordinarios avatares, cuando se cierre la divergencia entre los dos logos y la palabra filosófica regrese a su condición primera de palabra poética. Zambrano señala este paso del logos filosófico: "Y así aparece gracias al más renombrado de los filósofos de este siglo -Heidegger- que le es necesario volverse a la poesía, seguir los lugares del ser por ella señalados y visitados, para recobrarse, sin la certeza de lograrlo tal como lo lograron los presocráticos, en quienes la filosofía no se había desprendido aun de la poesía” (Bravo 124).

24 "La obra de vanguardia se ha definido como una creación inorgánica. Mientras que en la obra de arte orgánica el principio de construcción domina sobre la parte y la subordina a la unidad, en las obras de vanguardia las partes tienen una independencia esencial frente al todo; pierden valor como ingredientes de una totalidad de sentido y lo ganan como signos relativamente independientes” (Bürger 151).

$\begin{array}{lllll}\text { Revista Iberoamericana, Vol. LXXVI, Núms. 232-233 } & \text { Julio-Diciembre 2010, } & \text { 855-874 } \\ \text { ISSN 0034-9631 (Impreso) } & \text { ISSN 2154-4794 (Electrónico) }\end{array}$ 
su obra se presenta como una crisis de la representación, pero Juan Luis Martínez no proyecta su texto en la problemática de la realidad contingente, sino que indaga en la naturaleza de esa realidad desde una perspectiva metafísica. Martínez no quiere sino experimentar, jugar con los lenguajes, examinar la realidad desde la ciencia y la filosofía con una radicalidad estético-filosófica que carece de casi todo componente político comprometido. ${ }^{25}$ En Chile, La nueva novela ha sido el punto de referencia para entender la Neovanguardia de los años setenta y ochentas y su influjo se extiende a la poesía posterior de los años noventas. Junto a Diego Maquieira y Rodrigo Lira, Juan Luis Martínez aparece en este panorama como un poeta que propugna la autonomía del arte y practica una poesía experimental y agenérica. Sin embargo, a pesar de la apropiación del lenguaje y el saber científico que hace J.L. Martínez en este texto, el logro de $L a$ nueva novela no radica en las posibles respuestas que el lector pueda encontrar a las paradojas del texto, como ya hemos visto, sino en haber determinado que el fundamento de la realidad es también "la cosa del pensar" poético y que, finalmente, la realidad, en última instancia, rehuye revelar un fundamento de verdad y certidumbre tanto a la ciencia como a la poesía. La nueva novela es, desde este punto de vista, una forma de confirmar que sus propias paradojas no son más que la corroboración de la naturaleza paradojal de la realidad.

\section{BiBLIOGRAFÍA}

Barthes, Roland. "The Death of the Author”. Image, Music, Text. Stephen Heath, trad. New York: Hill and Wang, 1977.

Bravo, Víctor. "Del padecer y de la trascendencia”. Espéculo. Revista de estudios literarios 10 (1998).

Bunge, Mario. La ciencia. Su método y su filosofía. Buenos Aires: Editorial Sudamericana, 1995.

Bürger, Peter. Teoría de la vanguardia. Buenos Aires: Ediciones Península, 1987.

Burkhardt, Titus. Ciencia moderna y sabiduría tradicional. Madrid: Taurus Ediciones, 1979.

Carrasco, Iván. “Antipoesía y neovanguardia”. Estudios Filológicos 23 (1998): 35-53. "Poesía chilena de la última década (1977-1987)”. Revista Chilena de Literatura 33 (1989): 31-46.

\footnotetext{
25 "El concepto histórico de movimiento de vanguardia se distingue de tentativas neovanguardistas, como las que se dieron en Europa durante los años cincuenta y sesenta. Aunque la neovanguardia se propone los mismos objetivos que proclamaron los movimientos históricos de la vanguardia, la pretensión de un reingreso del arte en la praxis vital ya no puede plantearse seriamente en la sociedad existente, una vez que han fracaso las intenciones vanguardistas” (Bürger 54-5).
}

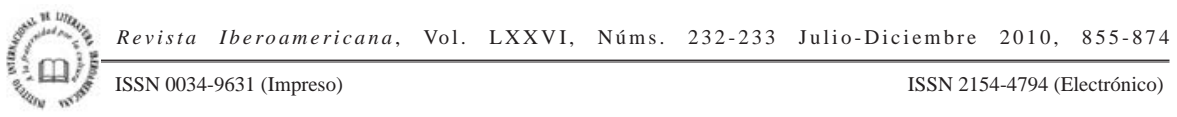


Daydi-Tolson, Santiago. "La obra de Juan Luis Martínez: un ejemplo de la poética chilena actual”. Romance Languages Annual 3 (1991): 406-10.

Eco, Umberto. The Open Work. Anna Concogni, trad. Cambridge: Harvard UP, 1989.

Einstein, Albert. Mi visión del mundo. Madrid: Tusquet Editores, 2005.

Espinosa, Julio. “Grupo poetas del 70 o la supuesta generación del 80”. Revista Galerna 3 (2005): 115-30.

Espinoza Orellana, Manuel. “La acción innovadora de Juan Luis Martínez”. El Espíritu del Valle, Santiago 4-5 (1998).

Estrella, Jorge. Ciencia y Filosofía. Santiago de Chile: Editorial Universitaria, 1982.

Fish, Stanley. "Literature in the Reader: Affective Stylistics". New Literary History 2/1 (Autumn 1970): 123-62.

Galindo, Oscar. "El alfabestiario universal de La nueva novela de Juan Luis Martínez”. Revista chilena de literatura 57 (2000): 21-40.

"Interdisciplinariedades de las poesías chilena e hispanoaméricana”. Estudios filológicos 39 (2004): 155-165.

Heidegger, Martín. Ser y Tiempo. José Luis Molinuelo, trad. Madrid: Tecnos, 2000. Carta sobre el Humanismo. Helena Cortés y Arturo Leyte, trads. Madrid: Alianza Editorial, 2000.

Ingarden, Roman. La comprehensión de la obra de arte literaria. Gerald Nyenhuis, trad. México: Universidad Iberoamericana, 2005.

Iser, Wolfgang. The Act of Reading. Theory of Aesthetic Response. Baltimore and London: The John Hopkins UP, 1978.

Jackson, Scott. "The Novelist of Non-Existence”. Revista Hispánica de Cultura 12 (1996): 134-40.

Joannon, Cristóbal. "Sonrisa de Gato". El Metropolitano (2 de abril de 2000).

Kirkpatrick, Gwen. "Desapariciones y ausencias en La nueva novela de Juan Luis Martínez”. Revista de Crítica Literaria Latinoamericana 50 (1999): 225-34.

Lastra, Pedro, y Enrique Lihn. Señales de ruta de Juan Luis Martínez. Santiago de Chile: Ediciones Archivo, 1987.

Martínez, Juan Luis. La nueva novela. Santiago de Chile: Ediciones Archivos, 1977. La poesía chilena. Santiago de Chile: Ediciones Archivos, 1978.

Merino, Roberto.”La pequeña casa del autor”. La Academia Imaginaria. Santiago de Chile. Octubre del 1998.

"Las expectativas de la recepción en La nueva novela de Juan Luis Martínez". La poesía chilena actual (1960-1984) y la crítica. Concepción: LAR Ediciones, 1988. 329-36.

Monarca, Patricia. "La deconstrucción del logos”. AEREA 1 (1997).

Monasterios, Elizabeth. "La nueva novela: el texto que ríe”. Revista Iberoamericana LX/168-169 (julio-diciembre 1994): 859-72.

Revista Iberoamericana, Vol. LXXVI, Núms. 232-233 Julio-Diciembre 2010, 855-874 
Morales, Andrés. "La poesía de la Generación de los 80: Valoración se fin de siglo”. Revista Aérea Año III/3 (2000): 242-8.

Muller and Halder. Diccionario de filosofía. Buenos Aires: Herder, 1981.

Paz, Octavio. Los privilegios de la vista I. Arte moderno universal. Obras Completas. Ciudad de México: FCE, 1993.

Rago, Héctor. "La ruptura imposible. Variaciones, reflexiones e interrogaciones sobre la física y las matemáticas”. Octava Jornada de Matemáticas. UCV. Caracas, 1995.

Rivas, Matías. “Notas para una entrevista”. El Mercurio (22 julio 2001).

Savory, Theodore H. The Language of Science. London: Andre Deutsch, 1967

Valdivieso, Jaime. “Juan Luis Martínez: Adiós a la cordura”. Merodeos en torno a la obra poética de Juan Luis Martínez. Soledad Fariña y Elvira Hernández, eds. Santiago de Chile: RIL Editores, 2001. 54-61.

Valente, Ignacio. “Juan Luis Martínez contra el olvido”. Revista de Libros. El Mercurio (29 de marzo de 2003).

Wittgenstein, Ludwig. Tractatus Logico-Philosophicus. Madrid:Alianza Editorial, 1987.

Revista Iberoamericana, Vol. LXXVI, Núms. 232-233 Julio-Diciembre 2010, 855-874
ISSN 2154-4794 (Electrónico) 